\title{
Research on the Risk Management of Stock Market Based on Macroeconomic Analysis
}

\author{
Wenting Jia
}

CIBC Mellon, Toronto, Canada, Postal Code: M5J0B6

Keywords: macroeconomic analysis; stock market; risk management

\begin{abstract}
In the risk assessment and analysis of the stock market, the macro analysis of the stock market is an effective analysis method. Macroeconomic analysis plays a very important role in promoting risk management in the stock market. Based on the current situation, this paper makes a full analysis of China's current stock market and determines how to manage the risk of the stock market in this economic situation.
\end{abstract}

\section{Research background}

In the important direction of the national economy, the stock market has a strong regulating effect on the development of the national economy, and contains an important stock value.The value of the stock consists of two sides. On the one hand, the analysis is conducted from the perspective of the model. For example, Zhao hua conducted extremely objective research on the current Chinese stock market. On the other hand, specific analysis is carried out on the basis of market information chain, which covers many researches on the stock market. By fully explaining and explaining these elements, the current research technology can be analyzed. The analysis here mainly refers to the data analysis and the research on the volatility variable of the stock through the statistical method. There is also the degree of correlation with other economic variables and the research on the model. As shown in figure 1, it is a method of mathematical statistics.

In addition, the description of current macroeconomic indicators also includes the research methods using corresponding models. The analysis of the stock market is a method to perfect and upgrade the research form of the stock market data. The measurement and management of stock market risk has also made some progress. Relevant scholars have carried out in-depth research on this management method and evaluated the risk of the stock market according to these aspects. The last is the application of VAR technology in stock market. This advanced theory realizes the measurement and basic management of market risk in the management of stock market.

\section{Macroeconomic analysis}

Macroeconomics is very comprehensive, and the current development situation includes many aspects. For example, the analysis of national fiscal policy and monetary policy has the shadow of macro-economy. This policy analysis covers several aspects. The values of these factors can be calculated by certain formulas. The formula for calculating the inflation rate is as follows:

$\mathrm{CPI}=\mathrm{a} 1(\mathrm{P} 1 \mathrm{t} / \mathrm{P} 10)+\mathrm{a} 2(\mathrm{P} 2 \mathrm{t} / \mathrm{P} 20)+\ldots . .+$ an $(\mathrm{Pnt} / \mathrm{Pn} 0)$

In today's development, the development of these policies has strong pertinence and guidance, which is of great significance for promoting the further development of China's current stock market. By using this method of policy analysis and macroeconomic variables, the current economic situation can be analyzed, which makes it convenient for us to monitor the risks through macroeconomic analysis.

\section{Current stock market policies}

China's current stock market policies have strong influence. The compulsion of state power plays an important role in the regulation and management of stock market policies. Effective management 
of false information can reduce the asymmetry of information spread in the market and gradually ensure that information is true and effective. We need to strengthen the formulation of policies in the stock market and carry out effective policy construction to promote the perfection of market policies.

\subsection{Macroeconomic variables and economic trends}

The real economy is one of the important conditions for the comprehensive development of financial market. In addition, the peripheral order of the real economy is also the basic condition for the development and stability of the financial market. The financial market under this condition is actually the market of financial capital transfer and financial redistribution. Among the elements that constitute the financial market, there are many macroeconomic variables that exert great influence on the trend of the macro economy. Therefore, we should carry out certain analysis and early warning on these macro indicators and urge relevant departments to take corresponding measures in a timely manner to control these macro economic indicators within the warning line and prevent the risk of the stock market from further expanding.

The above is the statistical chart of the growth rate of GDP data from the 20th century to the 21st century. As can be seen from figure 1, China's GDP has been in the trend of growth in the past few years, and reached the maximum value of 750 billion yuan in 2016 .
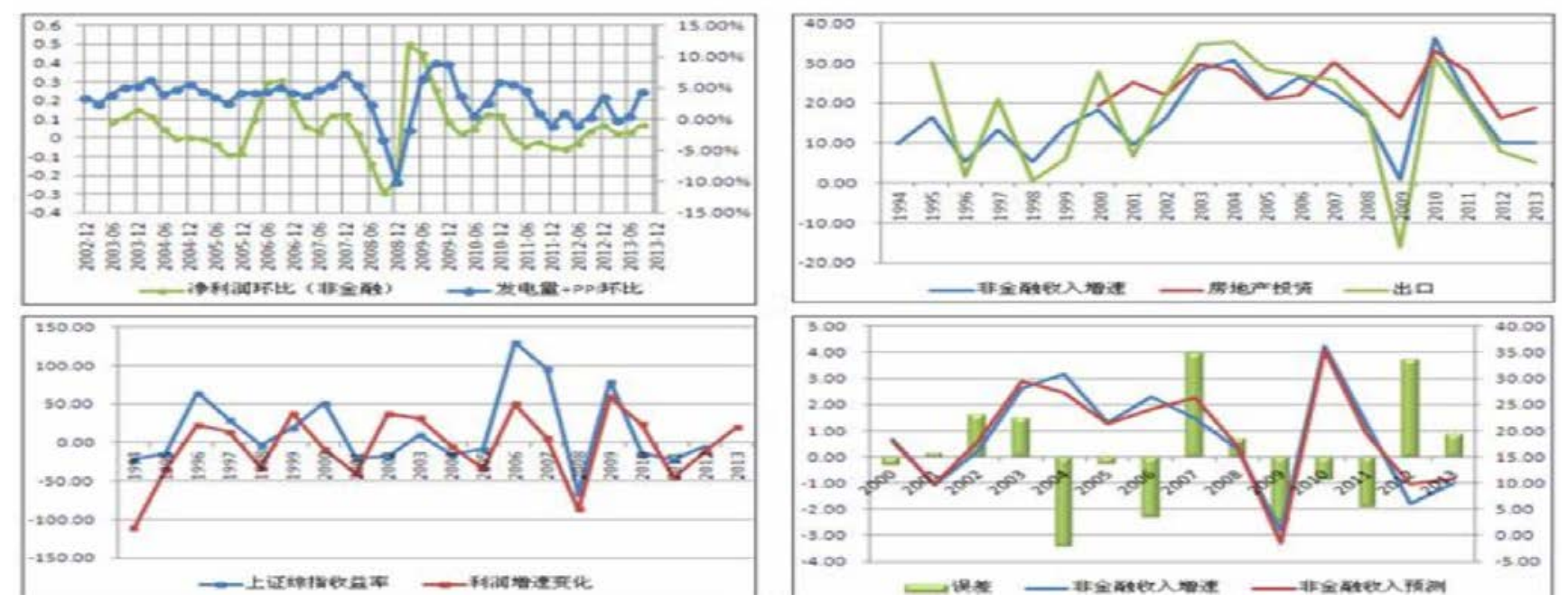

Figure 1: the impact of the economy on the stock market

\subsection{Risk management measures of stock market under macroeconomic analysis}

The data shown in figure 2 can be used as an illustration to analyze the stock trend. In the data shown in the figure, we can see the stock trend under the influence of the economy. In the figure at the top left, we can find the relationship between net profit and power generation. According to the trend of the two curves, we can find that the change trend of these two elements is roughly the same, and they are constantly influencing each other. In the chart at the top right, we can see the development and change curves of the three economies, namely non-financial income growth, real estate investment and export. Similarly, in the following lower left and lower right graphs, there are various economic factors that have different effects on the stock market.

Under the current macroeconomic situation, China's stock market has a strong systematic risk, and this risk is reflected in all aspects of the financial market, which also has a great impact on the stock market. Risk management is more achieved through targeted macro-regulation and improvement and treatment of laws and regulations. In the actual operation, the state realizes the macro control of the stock market through a certain real object. The currency plays an important role in the stock market as well as the relevant fiscal policies. 


\subsection{How to improve the macro-economy through macro-control and effectively reduce the market risk of stocks}

Monetary and fiscal policies can effectively reduce the inflation rate to a certain extent. In addition, these two policies also carry out necessary management and regulation on other aspects of the stock market. In the trading process of the stock market, how to guarantee the security of income distribution in the stock market is the practical problem that needs to be solved under the current macroeconomic situation. The stability of market operation can also improve the efficiency of market operation and reduce the risk effect of stock market. In the development of the stock market, macro-control may have a certain impact on the volatility of the stock market in the short term, and it has an adverse effect on the stability of the stock market. Therefore, in order to regulate the stock market, we should try our best to perfect the system of regulation and management of the stock market, and improve and adjust the interest rate and exchange rate through effective economic policies.

\subsection{How to promote the institutionalization of the stock market and reduce trading friction to maintain the smoothness of the stock market trading}

The stable operation of the stock market cannot be separated from the management of a complete system. Under the current macroeconomic regulation, the stock market is inseparable from the regulation of the system if it wants to achieve good development. In the stock market, the process of implementation of the management must pay attention to maintain the flow of stock market transactions. Stock trading market in the current construction mainly includes the following aspects.

Firstly, it is necessary to ensure the market operation of stock trading, and make full use of the market to provide a more secure environment for stock trading, so as to provide a more appropriate treatment for stock trading in the market. Secondly, in the operation of the stock market, we should strictly eliminate market manipulation and solve the stock safety problems of the citizens and prevent the occurrence of stock safety problems. Finally, the state should strengthen the further regulation of the stock market, carry out necessary analysis on the problems encountered in the current stock market, and make necessary generalizations about these problems.

\subsection{How to monitor and warn risks and prevent the transformation of non-system risk to system risk}

The four risk factors that influence stock returns are: stock size; Corporate capital structure ; Book value ratio. In order to study their effect on stock returns, this paper established 15 equations and studied the influence of four factors on stock returns through data regression.

$\begin{array}{lc}\mathrm{R}-\alpha+\beta \ln (\mathrm{ME}) & \text { (Equation 1) } \\ \mathrm{R}=\alpha+\chi(\mathrm{D} / \mathrm{E}) & \text { (Equation 2) } \\ \mathrm{R}=\alpha+\delta(\mathrm{E} / \mathrm{P}) & \text { (Equation 3) } \\ \mathrm{R}=\alpha+\varepsilon \ln (\mathrm{B} / \mathrm{M}) & \text { (Equation4) } \\ \mathrm{R}=\alpha+\beta \ln (\mathrm{ME})+\chi(\mathrm{D} / \mathrm{E}) & \text { (Equation5) } \\ \mathrm{R}=\alpha+\beta \ln (\mathrm{ME})+\delta(\mathrm{E} / \mathrm{P}) & \text { (Equation6) } \\ \mathrm{R}=\alpha+\beta \ln (\mathrm{ME})+\varepsilon \ln (\mathrm{B} / \mathrm{M}) & \text { (Equation) } \\ \mathrm{R}=\alpha+\chi(\mathrm{D} / \mathrm{E})+\delta(\mathrm{E} / \mathrm{P}) & \text { (Equation8) } \\ \mathrm{R}=\alpha+\chi(\mathrm{D} / \mathrm{E})+\varepsilon \ln (\mathrm{B} / \mathrm{M}) & \text { (Equation9) } \\ \mathrm{R}=\alpha+\delta(\mathrm{E} / \mathrm{P})+\varepsilon \ln (\mathrm{B} / \mathrm{M}) & \text { (Equation10) } \\ \mathrm{R}=\alpha+\beta \ln (\mathrm{ME})+\chi(\mathrm{D} / \mathrm{E})+\delta(\mathrm{E} / \mathrm{P}) & \text { (Equation11) } \\ \mathrm{R}=\alpha+\beta \ln (\mathrm{ME})+\chi(\mathrm{D} / \mathrm{E})+\varepsilon \ln (\mathrm{B} / \mathrm{M}) & \text { (Equation12) } \\ \mathrm{R}=\alpha+\beta \ln (\mathrm{ME})+\delta(\mathrm{E} / \mathrm{P})+\varepsilon \ln (\mathrm{B} / \mathrm{M}) & \text { (Equation13) } \\ \mathrm{R}=\alpha+\chi(\mathrm{D} / \mathrm{E})+\delta(\mathrm{E} / \mathrm{P})+\varepsilon \ln (\mathrm{B} / \mathrm{M}) & \text { (Equation14) } \\ \mathrm{R}=\alpha+\beta \ln (\mathrm{ME})+\chi(\mathrm{D} / \mathrm{E})+\delta(\mathrm{E} / \mathrm{P})+\varepsilon \ln (\mathrm{B} / \mathrm{M}) & \text { (Equation15) }\end{array}$

Alpha as constant, the beta for the market value of the natural logarithm is coefficient (ME), $\mathrm{Y}$ is the coefficient of financial leverage $(\mathrm{D} / \mathrm{E})$, the delta as the reciprocal of the $\mathrm{P} / \mathrm{E}$ ratio $(\mathrm{E} / \mathrm{P})$ 
coefficient, epsilon as the book value of the natural logarithm of $\ln$ coefficient (B/M). The above 15 equations were regression with sample data, and the analysis results in the following table were obtained.

\begin{tabular}{|c|c|c|c|c|c|}
\hline & Constant & $\ln (\mathrm{ME})$ & $\mathrm{D} / \mathrm{E}$ & $\mathrm{E} / \mathrm{P}$ & $\ln (\mathrm{B} / \mathrm{M})$ \\
\hline \multirow{2}{*}{ Equation1 } & 0.747357 & 0.046483 & & & \\
\hline & (1.917839) & $(-2.47442)$ & & & \\
\hline \multirow{2}{*}{ Equation2 } & 0.00467 & & -0.225626 & & \\
\hline & -3.49393 & & $(-19.740963)$ & & \\
\hline \multirow{2}{*}{ Equation3 } & -0.221702 & & & 0.546583 & \\
\hline & $(-19.295589)$ & & & $(-2.039128)$ & \\
\hline \multirow{2}{*}{ Equation4 } & -0.220103 & & & & -0.002375 \\
\hline & $(-10.494273)$ & & & & $(-0.203969)$ \\
\hline \multirow{2}{*}{ Equation5 } & 0.861518 & -0.05246 & 0.004992 & & \\
\hline & -2.228267 & $(-2.813052)$ & -3.742489 & & \\
\hline \multirow{2}{*}{ Equation6 } & 1.020735 & 0.060018 & & 0.762708 & \\
\hline & -2.552989 & $(-3.108760)$ & & -2.773314 & \\
\hline \multirow{2}{*}{ Equation7 } & 0.774404 & 0.774404 & & & -0.007098 \\
\hline & -1.973223 & -2.537652 & & & $(-0.604644)$ \\
\hline \multirow{2}{*}{ Equation8 } & -0.230995 & & 0.004702 & 0.556837 & \\
\hline & $(-19.776717)$ & & -3.526824 & -2.097463 & \\
\hline \multirow{2}{*}{ Equation9 } & -0.192021 & & 0.006063 & & 0.02389 \\
\hline & $(-8.760913)$ & & -3.928824 & & -1.795641 \\
\hline \multirow{2}{*}{ Equation10 } & -0.223188 & & & 0.545244 & -0.000986 \\
\hline & $(-10.641578)$ & & & -2.028876 & $(-0.084716)$ \\
\hline \multirow{2}{*}{ Equation11 } & 1.150642 & -0.066783 & 0.005124 & 0.79824 & \\
\hline & -2.901537 & $(-3.485513)$ & -3.863915 & -2.935248 & \\
\hline \multirow{2}{*}{ Equation12 } & 0.813348 & 0.04883 & 0.006091 & & 0.019237 \\
\hline & -2.097756 & $(-2.597121)$ & 3.966162 & & -1.43989 \\
\hline \multirow{2}{*}{ Equation13 } & 1.044291 & -0.061627 & & 0.75971 & -0.006464 \\
\hline & -2.595715 & $(-3.154702)$ & & 2.760239 & $(-0.553641)$ \\
\hline \multirow{2}{*}{ Equation14 } & -0.19464 & & 0.006226 & 0.59567 & 0.026111 \\
\hline & $(-8.898283)$ & & -4.043342 & -2.242974 & -1.963835 \\
\hline \multirow{2}{*}{ Equation15 } & 1.104793 & -0.06316 & 0.006322 & 0.816247 & 0.020915 \\
\hline & -2.78195 & $(-3.276959)$ & -4.139157 & -3.002608 & 1.574767 \\
\hline
\end{tabular}

By 15 equation of regression, we found that the influence stock returns four risk factors: the stock of natural logarithm scale, financial leverage, the p/e ratio and last book value than the natural logarithm of the first three are by $\mathrm{T}$ test. According to the results of regression, the size of stock market is negatively correlated with the return rate of stock.

When studying the relationship of stock returns as a single factor, the stock's financial leverage is negatively correlated with the stock returns. The regression analysis of stock p/e ratio and stock return rate found that there was significant positive correlation between both single factor analysis and multi-factor analysis, which was completely consistent with the research of a large number of other scholars.

The systematic risk in stock market is inevitable in stock trading, but the study of risk factors in stock market can provide necessary solutions for this prevention and cure. While preventing risks, we should actively seek ways to solve risks and prevent the occurrence of stock market crisis, which is conducive to preventing the spread of financial risks and transforming from 
non-systematic risk to systematic risk. It can be seen that risk prevention and monitoring work in the current stock market play an important role.

\section{Conclusion}

Under the current macroeconomic situation, how to make risk estimation is an urgent problem we need to solve in the current development of the stock market. And this method of managing stock market risk has achieved good results through macroeconomic analysis at present. In the future development, we should control the macro economy and manage the stock market risk better.

\section{References}

[1] Han Y. Thinking on the Supervision and Management of Stock Market in China[J]. Taxation \& Economy, 2000.

[2] Han, Y. (2000). Thinking on the supervision and management of stock market in china. Taxation \& Economy.

[3] Auribault E. Management of orders not accepted by the stock market at the level of an order server: US, US20070055614[P]. 2007.

[4] Kamel H, Elbanna S. Investigating the phenomenon of earnings management in the Egyptian stock market[J]. Corporate Governance International Journal of Business in Society, 2012, 12(3):337-352.

[5] Maupin R J. Financial and stock market variables as predictors of management buyouts[J]. Strategic Management Journal, 1987, 8(4):319-327.

[6] Bergh, D. D., \& Gibbons, P. (2011). The stock market reaction to the hiring of management consultants: a signalling theory approach. Journal of Management Studies, 48(3), 544-567. 